\title{
The Fountain of Health: effective health promotion knowledge transfer in individual primary care and group community-based formats
}

\author{
Amy Gough, ${ }^{1}$ Beverley Cassidy, ${ }^{1}$ Kiran Rabheru, ${ }^{2}$ David Conn, ${ }^{3}$ Donaldo D. Canales ${ }^{4}$ \\ and Keri-Leigh Cassidy' \\ ${ }^{1}$ Department of Psychiatry, Dalhousie University, Halifax, Nova Scotia, Canada \\ ${ }^{2}$ Department of Psychiatry, University of Ottawa, Ottawa, Ontario, Canada; The Ottawa Hospital, Ottawa, Ontario, Canada \\ ${ }^{3}$ Department of Psychiatry, Baycrest Centre, University of Toronto, Toronto, Ontario, Canada; Baycrest Health Sciences, Toronto, Ontario, Canada \\ ${ }^{4}$ Research Services, Saint fohn Regional Hospital, Saint fohn, New Brunswick, Canada
}

Background: The Fountain of Health (FoH) initiative is a knowledge transfer (KT) project on the science of brain health and resilience promotion, in alignment with positive psychiatry.

Objectives: Assess the effectiveness of FoH KT delivered in individual and group-based formats.

Design: Pre- and post-intervention quality assurance survey of FoH KT.

Setting: Interventions occurred in Nova Scotia, Canada.

Participants: Adults over age 50 years without pre-existing dementia were targeted. A total of 92 participants received FoH KT in individualized $(n=41)$ and group-based $(n=51)$ formats.

Intervention: FoH KT (e.g. sharing evidence, lifestyle coaching, and goal setting) using a range of KT supports (e.g. FoH website, paper materials) was delivered to (1) individual patients by primary care clinicians and (2) community-based groups by lay leaders.

Measurements: The main outcome measure was participant pre- and post-quality assurance self-reports.

Results: Improvements were found in participant awareness of $\mathrm{FoH}$, knowledge of evidence-based mental health promotion initiatives, and in application of this information in daily life in both individual and groupbased settings. Improvements in participant knowledge about epigenetic factors that impact health and confidence with health behavior goal setting were reported in both contexts. Changes in self-perceptions of aging scores reached significance in the group intervention.

Conclusions: FoH KT produced short-term positive self-reported changes in participants in both individual and group formats. Larger control studies with long-term follow up are needed to better assess effects of both individual and group formats of FoH KT and longer term impacts on health behaviors and outcomes.

Key words: positive psychiatry, healthy aging, mental health, dementia prevention

\section{Introduction}

The Fountain of Health $(\mathrm{FoH})$ is a Canadian initiative in applied "positive psychiatry," a newer branch of psychiatry dedicated to the science of mental health and well-being as outlined in Dr.

Correspondence should be addressed to: Amy Gough, MD, Department of Psychiatry, Dalhousie University, Room 6516, Abbie Lane Building, 5909 Veterans Memorial Lane, Halifax, Nova Scotia B3H 2E2, Canada. Phone: +1902-440-6373; Fax: +1-902-473-5713. Email: amy.gough@dal.ca. Received 15 Nov 2017; revision requested 26 Dec 2017; revised version received 3 Mar 2018; accepted 5 Mar 2018. First published online 25 May 2018.
Dilip Jeste's seminal book Positive Psychiatry (Jeste and Palmer, 2015). Founded in 2010 at Dalhousie University, $\mathrm{FoH}$ is a national non-profit organization to promote well-being across the lifespan. The FoH leadership team includes partners from academia, clinical medicine, and key organizations like the Canadian Mental Health Association, Canadian Coalition for Seniors Mental Health, and Canadian Medical Association. Funded through government sources and a Canadian Centre for Aging and Brain Health Innovation grant, $\mathrm{FoH}$ offers evidence-based knowledge transfer (KT) 
mechanisms (Malone et al., 2002; Bosma et al., 2011) to engage clinicians and the public to adopt lifestyle changes that can delay and prevent disease. FoH aligns with national (e.g. Dudgeon, 2010; MacCourt et al., 2011) and international guidelines urging mental health promotion in aging populations. The World Health Organization's (WHO) Global Age-Friendly Cities initiative (WHO, 2007) and Global Action Plan on the Public Health Response to dementia (WHO, 2017) emphasize a need for preventative approaches to dementia delay and prevention through lifestyle interventions.

$\mathrm{FoH}$ focuses on five evidence-based modifiable protective factors that promote mental well-being and resilience (Cassidy and Cassidy, 2018): outlook on aging (Rasmussen et al., 2009), physical activity (Thorp et al., 2011), social connection (Gilmour, 2012), cognitive activity (Jeste et al., 2010), and mental healthcare (Jeste et al., 2013; MorenoPeral et al., 2017). Positive attitudes on aging, for example, are associated with increased health behaviors even in the face of physical illness (Wurm et al., 2010), and with improved health outcomes including longevity (Levy et al., 2002a, 2002b), while negative attitudes are associated with worse health outcomes and reduced longevity (Wurm et al., 2013). FoH resources, including educational videos, a speakers' bureau, and selfguided educational tools and measures (e.g. healthy aging questionnaire and goal-setting) are accessible to both healthcare providers and general public online at www.fountainofhealth.ca.

Two distinct $\mathrm{KT}$ methods in $\mathrm{FoH}$ are those delivered by (1) frontline care clinicians to individual patients (Thoo et al., 2015) and by (2) lay leaders to participants in community-based groups (Gough and Cassidy, 2017). Both FoH KT methods appear promising: Thoo et al. (2015) reported highly significant differences in pre- and post-intervention scores of individual patients' knowledge and application of FoH. Similarly, Gough and Cassidy (2017) found significant differences in pre- and post-scores on measures of knowledge and outlook, and confidence in goalsetting among participants in group settings. FoH publications to date are among the first in applied positive psychiatry interventions in older adults to demonstrate improvements in health behaviors and well-being measures.

The present study substantially contributes to positive psychiatry literature, as well as to $\mathrm{KT}$ literature. To our knowledge, the present study is the first in geriatric positive psychiatry to compare effectiveness of two KT methods (individualized vs. group) for mental wellness promotion. Meanwhile, $\mathrm{KT}$ literature across medicine on the impact of $\mathrm{KT}$ on clinicians' translation into practice is lacking, and studies on KT impact on patient attitudes and behaviors are even more scarce. A review of KT resources within medicine demonstrated that only $20(4 \%)$ of 492 resources identified were relevant to seniors' mental health (Harris and Lusk, 2009).

The present study reports on the comparative effectiveness of two FoH interventions: (1) individual patients delivered by primary care clinicians and (2) community-based group participants delivered by lay leaders. The primary hypothesis was that individual and group-based KT interventions would both produce positive changes in patients' preto post-intervention knowledge, attitudes toward aging, and goal-setting for health promotion. Secondary hypotheses were that (1) individualized attention and tracking between clinical visits would be relatively more effective for activating healthpromoting goals and goal-attainment, and (2) community-based groups would be relatively more effective for improving participant attitudes toward aging and well-being.

\section{Methods}

In both individual and group-based $\mathrm{FoH} \mathrm{KT}$ interventions, common outcomes of health knowledge, goal-setting, goal-attainment, and changes to health outlook scores were compared. The two KT interventions were delivered as follows.

\section{Individual intervention}

Primary care clinicians delivered $\mathrm{FoH}$ education to patients in the course of routine care. Clinicians were recruited through professional contacts of project team members, expression of interest on the $\mathrm{FoH}$ website, and at Continuing Medical Education events. With no exclusion criteria or specific number of clinicians targeted but aiming for a total of 60 patients, clinicians were asked to offer $\mathrm{FoH}$ education to 5-10 cognitively intact patients over age 50 years who might benefit from lifestyle counseling. In the context of this quality assurance research and protecting patient confidentiality, no patient demographics were gathered.

To standardize the individual intervention, the project manager trained clinicians to use $\mathrm{FoH}$ materials through an in-person instruction, a 13min role-play video, and a "how-to" guide. The project manager supported clinicians throughout the process with check-ins by email or phone. Additional support materials (e.g. educational resources and clinical tools) were available to clinicians and patients on the $\mathrm{FoH}$ website. Feasibility of delivery in a primary care practice 
Table 1. S.M.A.R.T. goal-setting worksheet used with pilot project participants

\begin{tabular}{|c|c|}
\hline S.M.A.R.T. AREA & GUIDING QUESTION \\
\hline Goal/intention & $\begin{array}{l}\text { What would you like to accomplish in the next few months? } \\
\text { For example, social activity; physical activity; changing thoughts about aging; taking care of } \\
\text { mental health; learning new things. }\end{array}$ \\
\hline Specific & How specifically can you go about achieving this goal? What concrete steps would you need to take? \\
\hline Measurable & $\begin{array}{l}\text { How can you measure your progress? } \\
\text { How will you know when the goal is achieved? } \\
\text { (Can you rate your progress out of } 10 \text { ? How often or for how long will you do the activity?) }\end{array}$ \\
\hline Action-oriented & $\begin{array}{l}\text { Does the goal rely on an action that you can take? } \\
\text { What specific actions will you need to take? }\end{array}$ \\
\hline Realistic & $\begin{array}{l}\text { Is this goal realistic for you to achieve? } \\
\text { Is it doable in the next few weeks/months? }\end{array}$ \\
\hline Time-limited & $\begin{array}{l}\text { What timeframe does this goal require to achieve? } \\
\text { (When will you start/finish? What is the best time in the week?) }\end{array}$ \\
\hline
\end{tabular}

was a prime consideration in determining the intervention dose; the minimum contact required for clinicians to effectively introduce $\mathrm{FoH}$ content and support patients to set and meet health goals was selected. During the course of usual care, an initial 30-min appointment introduced the patient to $\mathrm{FoH}$, established a baseline, and allowed for "S.M.A.R.T." (i.e. specific, measurable, achievable, realistic, and time-limited) goal-setting (see Table 1). Two 10-15 min follow-up appointments were provided between one and three months' time to assess goal-attainment in evidence-based domains of positive psychiatry and to reassess patient behaviors and outlook.

\section{Group intervention}

Lay leaders delivered FoH education in a six-week group series to participants in the community. Lay leaders were recruited through online- and paperbased advertisements in senior-serving agencies, clubs, and public libraries. Potential lay leaders were invited to contact the project coordinator by email or telephone to sign-up. Groups of 6-10 participants over age 50 years were recruited using the same approach as above, and no exclusion criteria were applied.

In an effort to standardize group content delivery, lay leaders received a half-day orientation from the project manager, all necessary materials (i.e. PowerPoint slides, facilitator guide, and relevant handouts), and were supported by the project manager throughout. Each group series consisted of six-weekly $1.5-\mathrm{h}$ educational sessions. The dose selection of six $1.5-\mathrm{h}$ sessions was pragmatic, allowing for one introductory session on FoH and S.M.A.R.T. goal-setting, five sessions on each of the five FoH topics (social, physical, cognitive activity, mental health self-care, and positive outlook), and sufficient time for both content delivery and group discussion.

\section{Outcome measures}

The main outcome measure in both $\mathrm{KT}$ interventions was a quality assurance self-report questionnaire assessing health knowledge, attitudes, and behaviors pre- and post-intervention (see Table 2). Goal-attainment was assessed using a Likert scale on degree of goal-attainment post-intervention. The Levy et al. (2002a) self-perception of aging score used is based on the Attitudes Toward Own Aging subscale (Liang and Bollen, 1983), originally adapted from the Philadelphia Geriatric Center Morale Scale (Lawton, 1975). This fiveitem score provides a brief series of questions on self-perceptions of aging, and has been shown to correlate positively with increased longevity (Levy et al., 2002a; Table 3). The five items are summed to produce a total score out of five, with higher scores corresponding to more positive selfperceptions of aging.

\section{Ethics}

The Research Ethics Board at Dalhousie University reviewed the FoH quality assurance methods for individual and group KT approaches, and approved the project as quality assurance research given that the clinical intervention was health promotion education and occurred in routine care, neither KT format involved control groups, and no identifying patient or participant information was collected.

\section{Data analysis plan}

Changes in pre- and post-intervention questionnaire responses were analyzed using a two by 
Table 2. Questionnaire for participants (select items)

QUESTIONNAIRE ITEM

RESPONSE OPTIONS

1. I am aware of the Fountain of Health $(\mathrm{FoH})$ Initiative to promote mental/cognitive

True or false health in seniors

2. Currently, I apply information from the Fountain of Health $(\mathrm{FoH})$ initiative in my daily life.

3. What are evidence-based mental health promotion interventions outlined by the FoH?

True or false

4. The percentage of human longevity found to be determined by our genetics/family genes is:

Note: Additional items were included in each of the individual and group formats; only those questions that were asked in both settings and demonstrated positive improvements are highlighted in this paper.

Table 3. Questions on self-perceptions of aging (Levy et al., 2002b)

QUESTIONNAIRE ITEM

1. Things keep getting worse as I get older

2. I have as much pep as I did last year

3. As I get older, I'm less useful

4. I am as happy now as when I was younger

5. As I get older, things are (better, worse, or the same) as I thought they would be

Total score
RESPONSE OPTIONS (SCORE)

Yes $(0)$ or no (1)

Yes $(1)$ or no $(0)$

Yes $(0)$ or no (1)

Yes $(1)$ or no $(0)$

Better (1), worse (0), same (0) $0-5$

Note: For item 5, options "worse" or "same" were both scored as zero, to make the question a dichotomous variable. Participant scores ranged from 0 to 5, with 5 corresponding to more positive self-perception of aging. In Levy et al. (2002b), scores 3.67 and above at baseline were linked with a median survival 7.5 years longer compared with scores below this level.

two mixed analysis of variance. The within-group factor was assessment period (pre-intervention and post-intervention) and the between-groups factor was setting type (individual and group). Due to varying degrees of missing data and participant attrition at follow-up, changes in each of the six questionnaire items were examined separately. Alpha was set to 0.05 for all analyses. In addition, partial eta-squared $\left(\eta_{\mathrm{p}}{ }^{2}\right)$ effect sizes were also reported. Based on the effect size guidelines of Cohen (1988), $\eta_{\mathrm{p}}{ }^{2}$ values of $0.01,0.06$, and 0.14 correspond to small, medium, and large effect sizes, respectively.

\section{Results}

\section{Participants}

A total of 92 participants received FoH KT. Five lay leaders delivered five community-based $\mathrm{FoH}$ group series, reaching 51 participants. Six primary care clinicians provided individual KT to 41 patients. In the group setting, the majority of participants were females in both pre- $(N=39 ; 76.5 \%)$ and post- $(N=20 ; 74.1 \%)$ surveys. Group participants ranged from age 50 to 100 years, with only one participant (age 46 years) outside the target age group. Within the setting of this quality assurance study, no specific demographic data were collected on patients.

\section{Awareness of FoH}

This analysis was performed with 42 participants with complete data $(71 \%$ individual and $29 \%$ group). The main effect of assessment period was significant, $F(1,40)=57.52, \mathrm{p}<0.001$, $\eta_{\mathrm{p}}{ }^{2}=0.590$. Participants as a group had greater awareness of $\mathrm{FoH}$ in the post-intervention period $(M=0.94, S E=0.04)$ compared to the preintervention period $(M=0.26, S E=0.08)$. The main effect of setting was also significant, $F(1$, $40)=5.96, \mathrm{p}=0.019, \eta_{\mathrm{p}}{ }^{2}=0.130$. Overall, participants in the individual setting $(M=0.70$, $S E=0.04)$ had greater degree of FoH awareness compared to the group setting participants $(M=$ $0.50, S E=0.07)$. No significant interaction effect was observed $(\mathrm{p}=0.104)$.

\section{Application of FoH}

Analysis of $\mathrm{FoH}$ application was conducted with 36 participants with complete data $(67 \%$ individual and $33 \%$ group). Only the main effect of assessment period was significant, $F(1,34)=$ 87.43, $\mathrm{p}<0.001, \eta_{\mathrm{p}}{ }^{2}=0.720$. Compared to the pre-intervention period $(M=0.25, S E=$ 0.08 ), participants had significantly greater levels of application of $\mathrm{FoH}$ in the post-intervention period $(M=1.00, S E=0.00)$. No main effect of setting $(\mathrm{p}=0.306)$ or interaction effect $(\mathrm{p}=0.306)$ was found. 


\section{Goal-attainment}

In total, 41 participants set 53 S.M.A.R.T. goals (some patients setting multiple goals). Of 53 goals, over half $(n=31 ; 58.5 \%)$ were completely reached $(n=20 ; 37.7 \%)$ or exceeded $(n=11 ; 20.8 \%)$. Broad categories of goals included physical activity, social activity, changing thoughts about aging, mental health self-care, and learning new things. The majority of goals set $(n=30 ; 56.6 \%)$ were about physical activity (e.g. walk for $20 \mathrm{~min}$ thrice weekly for one week and participate in yoga for 60 min twice weekly over two months).

\section{Knowledge on evidence-based mental health promotion interventions}

This analysis was performed with 30 participants with complete data $(77 \%$ individual and $23 \%$ group). A main effect of assessment period was found, $F(1,28)=35.64, \mathrm{p}<0.001, \eta_{\mathrm{p}}{ }^{2}=$ 0.560 . The group-based participants had greater knowledge of evidence-based mental health promotion interventions post-intervention $(M=3.18$, $S E=0.32)$ compared to pre-intervention $(M=$ $0.86, S E=0.31)$. The main effect of setting was also significant, $F(1,28)=7.78, \mathrm{p}=0.009$, $\eta_{\mathrm{p}}{ }^{2}=0.217$. Independent of assessment period, participants in the group setting $(M=2.71, S E=$ 0.44 ) had greater overall knowledge relative to participants in the individual setting $(M=1.33$, $S E=0.24)$. No significant interaction effect was observed $(\mathrm{p}=0.178)$.

\section{Knowledge on the epigenetics of aging}

Knowledge of the epigenetics of aging was evaluated with 32 participants with complete data ( $84 \%$ individual and $16 \%$ group). Results indicated a main effect of assessment period, $F(1,30)=$ 40.88, $\mathrm{p}<0.001, \eta_{\mathrm{p}}{ }^{2}=0.577$, but no significant effect of setting $(\mathrm{p}=0.871)$. However, this finding was outweighed by a significant interaction, $F(1$, 30) $=7.11, \mathrm{p}=0.012, \eta_{\mathrm{p}}{ }^{2}=0.191$. Examination of the marginal means suggests that although knowledge increased among participants in the individual setting from pre-intervention $(M=1.67$, $S E=0.19)$ to post-intervention $(M=2.41, S E=$ $0.15)$, participants in the group setting had greater gains in knowledge from pre-intervention $(M=$ $1.20, S E=0.44)$ to post-intervention $(M=3.00$, $S E=0.35)$.

\section{Self-perceptions of aging}

This analysis was evaluated with 44 participants with complete data ( $73 \%$ individual; $27 \%$ group). Only the main effect of assessment period was significant, $F(1,42)=9.82, \mathrm{p}=0.003, \eta_{\mathrm{p}}{ }^{2}$
$=0.189$. Self-perceptions of aging in the postintervention period $(M=3.45, S E=0.26)$ were greater relative to the pre-intervention period $(M$ $=2.84, S E=0.26)$. A marginal main effect of setting, $F(1,42)=3.37, \mathrm{p}=0.074, \eta_{\mathrm{p}}{ }^{2}=0.074$, suggesting greater self-perceptions in the group setting $(M=3.58, S E=0.41)$ compared to the individual setting $(M=2.70, S E=0.25)$. Likewise, a marginal interaction effect emerged, $F(1,42)$ $=4.03, \mathrm{p}=0.051, \eta_{\mathrm{p}}{ }^{2}=0.088$, pointing to $\mathrm{a}$ potential increase in self-perceptions for the group setting participants (pre-intervention $M=3.08$, $S E=0.44$; post-intervention $M=4.08, S E=$ 0.44 ) but no such change in the individual setting participants (pre-intervention $M=2.59, S E=$ 0.27 ; post-intervention $M=2.81, S E=0.27$ ).

\section{Confidence in goal-setting}

Last, confidence in goal-setting was examined with 37 participants with complete data (81\% individual; $19 \%$ group). Neither main effects of assessment period $(\mathrm{p}=0.378)$ or setting $(\mathrm{p}=$ $0.440)$ nor interaction effects $(\mathrm{p}=0.156)$ were observed.

\section{Discussion}

The present study on the effectiveness of $\mathrm{FoH}$ positive psychiatry $\mathrm{KT}$ found both individual and group-based formats to be effective. Significant improvements were found in participants' selfreported: (1) awareness of $\mathrm{FoH}$, (2) application of $\mathrm{FoH}$ information into daily life, (3) knowledge of $\mathrm{FoH}$ and evidence-based health promotion factors, (4) knowledge about epigenetic factors in longevity, (5) confidence in health behavior goalsetting, and (6) self-perceptions of aging. FoH is the first initiative in applied positive psychiatry to demonstrate improvements in measures of wellbeing in older adults. $\mathrm{FoH}$ utilizes key approaches for successful KT: a supportive environment; content that is practice-based, high quality, and relevant to recipients; and effective facilitation appropriate to recipients (Malone et al., 2002; Bosma et al., 2011; Thoo et al., 2015). Present findings are consistent with the demonstration by Thoo et al. (2015) of highly significant differences in individual patients' knowledge and application of $\mathrm{FoH}$ in setting health goals as delivered by clinicians supported by a provincial KT network.

As hypothesized, differential and complementary benefits of two KT methods were found: individual KT delivered by a clinician resulted in enhanced goal-attainment, while attitudes were shifted more through peer-group interventions. For example, data on goal-achievement from the 
individual setting revealed that over half of patient goals were either completely reached or exceeded, suggesting effective $\mathrm{KT}$ to action in this setting. This finding is in accordance with prior reviews, suggesting that brief advice from a trusted careprovider significantly promotes health behavior change in patients (Stead et al., 2008). Of interest, response rates to the survey question on goalattainment were lower in the group setting relative to the individual setting. Reasons for this are unclear but might reflect a lack of participant clarity about setting or meeting health goals, or insufficient individualized attention on or "diffused responsibility" for these tasks within a group context. Further investigation on goal-attainment in both individual and group formats is needed.

In keeping with the study hypothesis, selfperceptions of aging improved in both individual and group settings but reached marginal statistical significance in the group format. This finding is notable given the association between higher selfperceptions of aging scores and increased longevity (Levy et al., 2002a), and also because they suggest that self-perceptions of aging are modifiable using a relatively brief $\mathrm{KT}$ intervention delivered by laypersons in the community. Beyond individuallevel benefits, improving self-perceptions of aging within communities is also consistent with the WHO's Global Age-Friendly Cities project (WHO, 2007), a strategy that aims to support psychosocial and physical health and improve quality of life in communities (Jeste et al., 2016; Gough and Cassidy, 2017).

In terms of explaining the differential impacts of the two KT methods, the fact that selfperceptions of aging scores increased toward marginal significance in the group but not the individual setting may be attributable to therapeutic factors specific to groups such as universality, instillation of hope, and role modeling (Yalom and Leszcz, 2008). The group setting also offered a higher "dose" of KT sessions (i.e. weekly sessions for six weeks vs. the individual $\mathrm{KT}$ via two to three clinician visits over a few months), which might have been beneficial in shifting outlook on aging. Knowledge improvements were also greater in the group setting, which might be attributable to the peer-learning format as well increased time to absorb information. It will be important to see whether these findings can be replicated in future FoH KT studies using controlled design and larger sample sizes.

Of note, the feasibility of the two KT approaches differed both in terms of human resource and costefficiency: reaching patients individually in formal healthcare settings via healthcare professionals required more resources than does a community, group-based intervention provided by lay leaders. One approach is not necessarily " "better" than the other but rather synergistic to support behavior change in older adults. For example, patients might be introduced to $\mathrm{FoH}$ domains by their primary care clinicians, and then become inspired by peers in a community-based group to join a local gym.

There are clear limitations of these findings, as they are based on short-term self-reported quality assurance data with no control group. Regarding participants, selection bias exists in both contexts: at the individual level, participants were selected by clinicians based on potential benefit from health promotion education, and community group participants were self-selected volunteers. In the individual quality assurance intervention, patient demographics were not controlled for. In the group setting, there were generally lower response rates from pre- to post-KT intervention. Results were tracked by patients/group participants receiving the $\mathrm{KT}$ but not controlled for the individual clinicians and lay leaders delivering the KT.

To address these limitations in future studies, results would be strengthened in a randomized controlled design comparing the two interventions directly across multiple settings, and using objective outcome measures in addition to self-report. Future outcome measures could include quality of life, resilience, and objective behavior change. Additional control variables could include the following: demographic variables; age groups; participants' characteristics, including overall health status; and characteristics of or variation in results by an individual KT facilitator. Longer follow-up would allow for assessment of sustained behavior change over time and related impact on longer term health outcomes. Future studies could explore reasons for lower response rates seen in the group setting, and/or modify interventions to improve efficiency and outcomes. For example, modifying groups to enhance accountability for goal-setting and attainment, or modifying individual interventions to involve more reflection opportunities to shift attitudes, could be explored. One FoH project currently underway to improve efficiency involves a shorter 10-min intervention in primary care settings, with promising preliminary results suggesting the potential for positive impacts from even briefer interventions in routine care. FoH is actively pursuing partnerships with several key national healthcare organizations to promote national $\mathrm{KT}$ of $\mathrm{FoH}$ and mental and physical health of Canada's seniors.

In the context of an aging world population and an international call to promote healthy aging, the positive psychiatry movement offers a shift in medicine from reactive pathology-focused 
treatment to inclusion of proactive health promotion in routine care. FoH offers tools for applied positive psychiatry using evidence-based techniques to promote mental wellness at the individual and community levels. The present analysis indicates that $\mathrm{FoH}$ tools promote positive health outlook and behavior and can be effectively delivered in both individual clinical care and community-based groups. FoH's pragmatic and efficient mental health promotion KT tools invite a culture shift across healthcare and community through inclusion of resilience and mental wellness promotion. This work is novel in assessing impacts of KT on health outlooks and behaviors and identifies many topics of interest for further exploration in the young body of research on $\mathrm{KT}$ applications for seniors' mental health.

\section{Conclusion}

In conclusion, the current study found that $\mathrm{FoH}$ educational interventions produced significantly positive changes using evidence-based health promotion tools in both individual and communitygroup formats. The effectiveness of both KT approaches was significant, but it also revealed differential and complementary benefits.

FoH demonstrates promise for modifying psychosocial factors associated with healthy aging and improved longevity, including positive selfperceptions of aging and promoting health behavior activation. Additional research is needed to assess the potential for enhanced resilience and behavior change in a larger sample and across time and settings in order to more fully assess the impact of $\mathrm{FoH}$ in supporting positive aging, fostering mental wellness in later life and in delaying or preventing illness. All of the $\mathrm{FoH}$ information and resources are publically accessible through the website www.fountainofhealth.ca.

\section{Conflict of interest}

None.

\section{Description of authors' roles}

Dr. A. Gough performed data analysis and contributed substantially to writing and produced the first draft of the paper. Dr. B. Cassidy, Dr. K. Rabheru, and Dr. D. Conn are the core members of the Fountain of Health national leadership team who contributed substantially to the writing and editing. Mr. D. D. Canales advised and assisted with the statistical methods, analyses, and reporting. Dr. K.-L. Cassidy, who is the founder of the Fountain of Health, conceptualized the study, supervised data analysis, and contributed substantially to writing and editing.

\section{Acknowledgments}

The Nova Scotia Department of Health and Wellness and Department of Seniors are acknowledged for their grants supporting the FoH's KT projects.

\section{References}

Bosma, M., Cassidy, K.-L., Le Clair, J. K., Helsdingen, S. and Devichand, P. (2011). A knowledge transfer study of the utility of the Nova Scotia Seniors' mental health network in implementing seniors' mental health national guidelines. Canadian Geriatrics fournal, 1, 1-5.

Cassidy, K.-L. and Cassidy, B. (2018). Positive psychiatry. In K. Fountoulakis and A. Javed (eds.), Advances in Psychiatry. Cham, Switzerland: Springer International Publishing AG.

Cohen, J. (1988). Statistical Power Analyses for the Social Sciences. Hillsdale, NJ: Lawrence Erlbauni Associates.

Dudgeon, S. (2010). Rising Tide: The Impact of Dementia on Canadian Society: A Study. Toronto, Ontario: Alzheimer Society of Canada.

Gilmour, H. (2012). Social participation and the health and well-being of Canadian seniors. Health Reports, 23, $1 \mathrm{~B}$.

Gough, A. and Cassidy, K.-L. (2017). Toward psychosocial health in age-friendly communities: the fountain of health peer-led education series. Mental Health and Prevention, 8, 14-19.

Harris, M. and Lusk, E. (2009). The Road Ahead: A Knowledge Bank Progress Report. Ottawa: The Knowledge Bank. Available at: http://citeseerx.ist.psu.edu/viewdoc/ download?doi=10.1.1.540.7123\&rep=rep1\&type=pdf; last accessed 26 February, 2018.

Jeste, D. V. et al. (2013). Association between older age and more successful aging: critical role of resilience and depression. American fournal of Psychiatry, 170, 188-196.

Jeste, D. V. et al. (2016). Age-friendly communities initiative: public health approach to promoting successful aging. American fournal of Geriatric Psychiatry, 24, 1158-1170.

Jeste, D. V., Depp, C. A. and Vahia, I. V. (2010). Successful cognitive and emotional aging. World Psychiatry, $9,78-84$.

Jeste, D. V. and Palmer, B. W. (eds.) (2015). Positive Psychiatry: A Clinical Handbook. Arlington: American Psychiatric Publishing.

Lawton, M. P. (1975). The Philadelphia Geriatric Center Morale Scale: a revision. Fournal of Gerontology, 30, 85-89.

Levy, B. R., Slade, M. D. and Kas1, S. V. (2002b). Longitudinal benefit of positive self-perceptions of aging on functional health. Fournal of Gerontology B Psychological Sciences and Social Sciences, 57, 409-417.

Levy, B. R., Slade, M. D., Kunkel, S. and Kas1, S. (2002a). Longevity increased by positive self-perceptions of aging. Fournal of Personality and Social Psychology, 83, 261-270. 
Liang, J. and Bollen, K. A. (1983). The structure of the Philadelphia Geriatric Center Morale Scale: a reinterpretation. Fournal of Gerontology, 38, 181-189.

MacCourt, P., Wilson, K. and Tourigny-Rivard, M.-F. (2011). Guidelines for Comprehensive Mental Health Services for Older Adults in Canada. Calgary, AB: Mental Health Commission of Canada. Available at: http://www.mentalhealthcommission.ca

Malone, J. et al. (2002). Ingredients for change: revisiting a conceptual framework. Quality $\&$ Safety in Health Care, 11, 174-180.

Moreno-Peral, P. et al. (2017). Effectiveness of psychological and/or educational interventions in the prevention of anxiety: a systematic review, meta-analysis, and meta-regression. $\mathcal{F} A M A$ Psychiatry, 74, 1021-1029.

Rasmussen, H. N., Scheier, M. F. and Greenhouse, J. B. (2009). Optimism and physical health: a meta-analytic review. Annals of Behavioral Medicine, 37, 239-256.

Statistics Canada (2015). Population projections for Canada (2013 to 2063), provinces and territories (2013 to 2038). Available at: http://www.statcan.gc.ca/pub/91-520-x/ 91-520-x2014001-eng.pdf; last accessed 15 December 2016.

Stead, L. F., Bergson, G. and Lancaster, T. (2008). Physician advice for smoking cessation. Cochrane Database of Systematic Reviews, 2, 4-8.
Thoo, V., Freer, J. and Cassidy, K.-L. (2015). The fountain of health: bringing seniors' mental health promotion into clinical practice. Canadian Geriatrics fournal, 18, 217-224.

Thorp, A. A. et al. (2011). Sedentary behaviors and subsequent health outcomes in adults a systematic review of longitudinal studies, 1996-2011. American fournal of Preventive Medicine, 41, 207-215.

World Health Organization (2007). Global Age-Friendly Cities: A Guide. Geneva: World Health Organization. Available at: http://www.who.int/ageing/publications/ Global_age_friendly_cities_Guide_English.pdf?ua=1; last accessed 15 December 2016.

World Health Organization (2017). Global Action Plan on the Public Health Response to Dementia: 2017-2025. Available at: http://apps.who.int/gb/ebwha/pdf_files/EB140/ B140_28-en.pdf?ua=1; last accessed 13 November 2017.

Wurm, S., Thomasik, M. J. and Tesch-Romer, C. (2010). On the importance of a positive view on ageing for physical exercise among middle-aged and older adults: cross-sectional and longitudinal findings. Psychology $\mathcal{E}$ Health, 25, 25-42.

Wurm, S., Warner, L. M., Ziegelmann, J. P., Wolff, J. K. and Schüz, B. (2013). How do negative self-perceptions of aging become a self-fulfilling prophecy? Psychology and Aging, 28, 1088-1097.

Yalom, I. and Leszcz, M. (2008). The Theory and Practice of Group Psychotherapy, 5th ed. New York: Basic Books. 